\title{
A EDUCAÇÃO NO BRASIL COLONIAL: REVISÃO BIBLIOGRÁFICA E CAMINHOS PARA PESQUISAS NA AMAZÔNIA
}

\author{
Maria Betânia Barbosa Albuquerque* \\ Jane Elisa Otomar Buecke*
}

\section{RESUMO}

Este artigo analisa fontes e possibilidades de pesquisa educacional no Brasil colonial, particularmente, na Amazônia. Origina-se de uma investigação de natureza teóricobibliográfica, considerando relatos de viagens, cartas jesuíticas, dissertações, teses e artigos. Notamos o protagonismo dos jesuítas e da educação institucionalizada por eles, emergindo, assim, lacunas no campo das ações educativas promovidas por outras ordens religiosas e dos estudos sobre processos educativos ocorridos no cotidiano social passado.

Palavras-chave: história da educação, Amazônia colonial, educação colonial.

"Universidade do Estado do Pará (UEPA), Belém/PA, Brasil.

${ }^{* *}$ Universidade do Estado do Pará (UEPA), Belém/PA, Brasil. 


\title{
EDUCACIÓN EN BRASIL COLONIAL: REVISIÓN BIBLIOGRÁFICA Y FORMAS DE INVESTIGACIÓN EN LA AMAZONÍA
}

\section{RESUMEN}

Este artículo analiza las fuentes y posibilidades de la investigación educativa en el Brasil colonial, particularmente en la Amazonía. Se origina a partir de una investigación teóricobibliográfica, considerando reportajes de viaje, cartas jesuitas, disertaciones, tesis y artículos. Notamos el protagonismo de los jesuitas y la educación institucionalizada por ellos, emergiendo así brechas en el campo de las acciones educativas impulsadas por otras órdenes religiosas y estudios sobre los procesos educativos que se desarrollaban en la vida social cotidiana.

Palabras clave: historia de la educación, Amazonía colonial, educación colonial.

\section{EDUCATION IN COLONIAL BRAZIL: BIBLIOGRAPHIC REVIEW AND WAYS OF RESEARCH IN THE AMAZON}

\begin{abstract}
This article analyzes sources and possibilities for educational research in colonial Brazil, particularly in the Amazon. It originates from a theoretical-bibliographic investigation, considering travel reports, Jesuit letters, dissertations, theses and articles. We note the protagonism of the Jesuits and the institutionalized education for them, thus emerging gaps in the field of educational actions promoted by other religious orders and studies on educational processes that took place in daily social life
\end{abstract}

Keywords: history of education, colonial Amazonia, colonial education.

\section{ÉDUCATION AU BRÉSIL COLONIAL: REVUE BIBLIOGRAPHIQUE ET PISTES DE RECHERCHE EN AMAZONIE}

\section{RÉSUMÉ}

Cet article analyse les sources et les possibilités de recherche pédagogique au Brésil colonial, en particulier en Amazonie. Il provient d'une enquête théorico-bibliographique, prenant en compte les rapports de voyage, les lettres jésuites, les dissertations, les thèses et les articles. Nous notons le protagonisme des jésuites et l'éducation institutionnalisée pour eux, d'où des lacunes émergentes dans le domaine des actions éducatives promues par d'autres ordres religieux et des études sur les processus éducatifs qui ont eu lieu dans la vie sociale quotidienne.

Mots-clés: histoire de l'éducation, Amazonie coloniale, éducation coloniale. 


\section{INTRODUÇÃO}

Este artigo tem por objetivo refletir sobre fontes e possibilidades de pesquisa educacional situada no Brasil colonial, em particular, na Amazônia. Resulta de uma pesquisa de natureza teórico-bibliográfica à semelhança dos estudos sobre o estado do conhecimento. Segundo Ferreira (2002, p. 258), tais estudos apresentam o desafio de

[...] mapear e de discutir uma certa produção acadêmica em diferentes campos do conhecimento, tentando responder que aspectos e dimensões vêm sendo destacados e privilegiados em diferentes épocas e lugares, de que formas e em que condições têm sido produzidas certas dissertações de mestrado, teses de doutorado, publicações em periódicos e comunicações em anais de congressos e de seminários.

Voltamo-nos para as pesquisas educacionais no período colonial por suspeitar, junto a outros intelectuais, que este parece ser um período que ainda não despertou o devido interesse dos pesquisadores da história da educação. Prova disso são os poucos trabalhos nele ambientados, fato perceptível, por exemplo, nos Congressos Brasileiros de História da Educação - CBHE’s, organizados pela Sociedade Brasileira de História da Educação em que, dos 4.605 trabalhos apresentados nas nove edições do evento realizadas de 2000 à 2015, menos de 2\% tratavam desse período histórico (BUECKE, 2019).

De acordo com Fonseca (2009), o mesmo ocorre em outros eventos importantes no âmbito da história da educação, como é o caso do Congresso Luso-Brasileiro de História da Educação, e nos eventos organizados pela Associação Nacional de História. Segundo Bittar e Ferreira (2010), a pouca incursão das pesquisas no período colonial ocorre pela falsa impressão de que não há nada mais a se acrescentar no que se refere à educação realizada nesse contexto. As pesquisas existentes se concentram, principalmente, na atuação educacional dos jesuítas, fato denunciado por Sangenis e Maynka (2019, p. 6) em estudo detalhado sobre os 26 trabalhos encontrados nas 9 edições dos 
CBHE's, de 2000 a 2017, que abordam o período colonial. Segundo análise dos autores:

\begin{abstract}
A maioria dos trabalhos é dedicada à época contemporânea. Dos relativamente poucos trabalhos dirigidos ao período colonial, a maioria avassaladora se debruça sobre questões relacionadas com a Companhia de Jesus, a sua atuação na conquista e colonização, a evangelização e catequese dos gentios, a sua domesticação e civilização, a sua cooperação com as autoridades seculares, em detrimento das outras ordens religiosas, nomeadamente da Ordem dos Frades Menores (OFM) e dos seus diferentes ramos.
\end{abstract}

Contudo, para além de uma perspectiva extremista que, de um lado, considera o trabalho dos jesuítas como essencial à educação brasileira e, de outro, o considera totalmente prejudicial, há uma gama de interpretações que precisam ser consideradas e revisitadas a fim de desmitificar o papel da Companhia de Jesus na Educação Colonial e enriquecer tal discussão. Entre essas possibilidades, destacamos a educação ocorrida no cotidiano social dos aldeamentos, por exemplo, como um objeto de pesquisa ainda pouco estudado (BUECKE, 2019).

Se no âmbito nacional, a existência de pesquisas abordando a educação no período colonial é exígua e pulverizada, ao reduzirmos o campo de análise para o espaço amazônico, tal escassez de trabalhos se torna mais patente. Como hipóteses explicativas para essa diferença, podemos elencar o início tardio da colonização no século XVII e a chegada, também tardia, dos Programas de PósGraduação na região nos anos 2000 de onde emerge parte considerável da produção intelectual em educação. Outro aspecto, porém, que tem sobressaído na discussão sobre as dificuldades de pesquisas educacionais situadas no período colonial, refere-se às fontes, consideradas poucas, inacessíveis, e/ou em mau estado de conservação (SILVA, 2006).

Nesse sentido, a fim de contribuir com as pesquisas sobre a história da educação no período colonial, particularmente, na Amazônia, realizamos um 
levantamento bibliográfico no banco de teses da Capes, no Google Acadêmico, bem como nos Programas de Pós-Graduação em Educação e História do Estado do Pará, utilizando o descritor Educação Colonial.

O levantamento evidenciou a existência de poucos trabalhos abordando essa temática e destacou a primazia dos historiadores no tratamento do tema. Entretanto, a bibliografia encontrada no referido levantamento, ainda que escassa, demonstra o esforço de alguns pesquisadores em descortinar processos educativos no período colonial amazônico, conforme procuramos destacar neste texto.

\title{
FONTES PARA O ESTUDO DA EDUCAÇÃO NO PERÍODO COLONIAL
}

O conhecimento aprofundado da ação pedagógica dos jesuítas é considerado por Bittar e Ferreira (2010), a porta de entrada para entender a educação colonial. E, neste caso, incluímos também a educação cotidiana, que não se restringe à formação ensinada nos colégios jesuítas. Por sua amplitude, teoricamente esse tipo de educação como prática social:

\begin{abstract}
se relaciona com conceitos correntes no campo da Pedagogia que expressam um significado ampliado para a formação humana com base em processos de ensino e aprendizagem diversificados, complexos, dinâmicos e interconectados em espaços e tempos distintos da instituição escolar, a exemplo dos conceitos de Educação Permanente, Educação ao Longo da Vida, Educação Integral, Educação Social, dentre outros (SEVERO, 2018, p. 6).
\end{abstract}

A educação ocorrida no cotidiano desponta, assim, como uma possibilidade de pesquisa sobre o passado colonial brasileiro, e as cartas jesuíticas emergem como fontes a revisitar, uma vez que: 
Essas e outras 'páginas' da história da educação brasileira nos seus primeiros dois séculos encontram-se em fontes primárias impressas como as que acabamos de citar [cartas jesuíticas] e nos propiciam um quadro cultural bastante revelador sobre as circunstâncias em que ela transcorria. Assim, quando nos indagam por que desejamos retomar estudos que já 'receberam ampla revisão', respondemos que assim o fazemos porque ainda não foram suficientemente pesquisados, exigem compreensão e merecem uma visão de conjunto. Neste sentido, quando apontamos para os documentos de época como fonte principal da pesquisa, desejamos chamar a atenção para o pouco que ainda se conhece sobre esse passado (BITTAR; FERREIRA, 2010, p. 19).

Nesse sentido, os autores ressaltam os documentos produzidos pelos padres jesuítas, bem como os diversos relatos dos europeus que viajaram pela colônia portuguesa no Brasil, como importantes fontes de pesquisa para a compreensão da história da educação ocorrida naquele período. Além dos inacianos, outras ordens mantiveram missões evangelísticas no Brasil e também deixaram importantes registros que podem contribuir com diversos estudos no campo educacional.

Dentre as obras franciscanas podemos citar o Novo Orbe Seráfico Brasílico ou Chronica dos frades menores da Província do Brasil de Frei Antônio de Santa Maria Jaboatão. Nascido em Pernambuco em 1695, entrou para a Ordem dos Franciscanos em 1717, na qual exerceu vários cargos até sua morte em 1779. Lins (2013, p. 359) considera a obra de Frei Antônio referência obrigatória para os estudiosos sobre a Ordem Franciscana e a resume como

\footnotetext{
uma primorosa produção, pesquisada e documentada, originada, em parte, de consultas que o autor empreendeu junto a obras literárias lusitanas e brasileiras, incluindo fontes manuscritas dos arquivos públicos e religiosos de Pernambuco, Bahia, Paraíba e Sergipe. Também foram aproveitadas fontes orais, relacionadas à história da Ordem franciscana no Brasil e também da sociedade brasileira, durante o Período Colonial.
}

Cabe mencionar ainda, a História do Brasil de Frei Vicente do Salvador publicado pela editora do Senado Federal, estando disponível também em 
domínio público. Embora não seja uma crônica, trata-se de uma fonte que pode contribuir com as pesquisas educacionais no período colonial.

Natural de Salvador, Frei Vicente iniciou sua formação intelectual no colégio jesuíta da capital baiana, dando seguimento em Coimbra onde concluiu o doutorado em Teologia. De volta ao Brasil, exerceu vários cargos religiosos e, em 1620, começou a se dedicar à escrita do seu livro. Para isso, "viaja constantemente entre missões, assumindo cargos e lidando com assuntos eclesiásticos em várias capitanias" (SOUZA, 2016, p. 20). Seu livro aborda a história do descobrimento do Brasil, detalhando as características das terras e povos encontrados, a expansão do território durante os primeiros governos gerais, bem como os conflitos ocorridos nesse intento. O período de análise se encerra quando o Estado do Maranhão ainda estava se organizando, motivo pelo qual há apenas cinco capítulos versando sobre essa região e o processo de conquista do território.

Um dos primeiros jesuítas a se estabelecer no norte do Brasil foi o padre Luís Figueira. Ao se instalar no Ceará, ele escreveu A Relação do Maranhão (1887) com o objetivo de comunicar aos seus superiores em Portugal os detalhes da missão. Este documento configura-se como importante fonte de pesquisa por abordar "uma ampla gama de estudos que abrangem a História, a Historiografia, a Linguística, a Etnografia e a Filologia, entre inúmeros outros" (SILVA;CAVALCANTE, 2012, p. 12).

Outra obra relevante do padre Luís Figueira é $A$ arte da língua brasílica, uma gramática da Língua Portuguesa que visou prover a comunicação com os indígenas do norte do Brasil. Nela, está registrada a gênese da língua falada na região possibilitando a compreensão de aspectos históricos que permearam e motivaram sua elaboração.

Aos nos referirmos, particularmente, ao contexto amazônico, destacamse a História da missão dos padres capuchinhos na ilha do Maranhão e suas circunvisinhanças, escrita pelo padre capuchinho Claude D’Abbeville (1874), no início do século XVII, bem como a Continuação da história das coisas mais 
memoráveis acontecidas no Maranhão nos anos 1613 e 1614 (2007), do também capuchinho Yves D’Évreux, escrita no mesmo período. Tais fontes são acessíveis por estarem publicadas e sua importância reside no fato de relatarem o contato, a convivência e as impressões desses padres sobre os nativos. Os padres capuchinhos Claude D’Abbeville e Ives D'Évreux faziam parte da missão organizada por Daniel de La Touche que intentou implantar uma colônia francesa na região norte do Brasil - A França Equinocial (1612-1615).

O texto de Abbeville foi produzido nos quatro meses que permaneceu no Maranhão, tendo sido publicado com sucesso na França em 1614. Trata-se de um monumento de 403 páginas, com detalhes sobre os costumes indígenas e seus ritos "abomináveis" - as beberagens. Em 1874, teve sua primeira tradução para o Português, realizada por Cesar Augusto Marques, no Maranhão (ABBEVILLE, 1874).

Já o padre Évreux permaneceu dois anos na região liderando a missão e escreveu o que ele mesmo chamou de Continuação da história das coisas mais memoráveis acontecidas no Maranhão nos anos 1613 e 1614 por considerar seu texto capaz de acrescentar o que Abbeville deixara de fora. Todavia, ao contrário do seu companheiro, não teve a oportunidade de ver sua Crônica publicada (ÉVREUX, 2007). A primeira publicação foi confiscada porquanto não interessava à França, naquele momento, criar atritos com a Espanha que era a dona "legal" das colônias portuguesas devido à União Ibérica. Isto porque o futuro rei da França já havia acertado casamento com a princesa espanhola da Áustria.

Entretanto, graças às divergências internas e, especificamente, ao interesse do almirante François de Razzili na colonização do Maranhão, algumas cópias da obra foram resgatadas antes de serem destruídas. Uma delas foi presenteada ao rei Luís XIII, ficando esquecida em sua biblioteca pessoal. Conservado na Biblioteca Imperial, esse exemplar foi encontrado pelo historiador Ferdinand Denis e publicado em Português em 1874 (ÉVREUX, 2007). 
Outra fonte que importa considerar é a História dos animais e árvores do Maranhão (1967), de Frei Cristóvão de Lisboa, franciscano português que chegou ao Brasil em 2 de maio de 1624 com o objetivo de evangelizar os índios aqui encontrados. Na sua missão evangelizadora, andou pelo norte do Brasil durante os dois primeiros anos de sua estada no Maranhão, quando possivelmente se dedicou a desenhar e descrever sobre plantas e animais que lhes pareciam exóticos. Ainda que sua obra não aborde diretamente sobre processos educativos, sua História dos animais e árvores do Maranhão, escrita, presumivelmente, entre 1624 e 1627, é um manancial de saberes a respeito da natureza que as populações autóctones detinham antes da chegada dos europeus ao território brasileiro.

Dentre os escritos jesuíticos referentes à Amazônia Colonial, se destaca a Crônica dos padres da Companhia de Jesus no Estado do Maranhão, escrita pelo padre João Felipe Bettendorff, no final da sua vida como missionário na Amazônia. Nela, são narradas as ações dos jesuítas desde as primeiras tentativas de se instalarem na região no século XVII. Mostra o modo de vida dos habitantes locais e detalha situações que permitem adentrar no cotidiano da vida na Amazônia daquele período.

Biógrafo de Bettendorff, o historiador Karl Arenz o considera personagem chave para o entendimento da formação da sociedade colonial, principalmente pela consolidação da Missão no Estado do Maranhão na Amazônia seiscentista. Para ele:

além de aspectos específicos (religiosos, econômicos, sócio-políticos, jurídicos, etnográficos, geográficos) a crônica apresenta uma visão geral da formação da sociedade colonial e aponta para as transformações ocorridas no mundo ameríndio no século XVII (ARENZ, 2010, p. 60).

Bettendorff, um jovem missionário jesuíta nascido em Luxemburgo em 1625, veio para o Brasil a fim de trabalhar nas missões do Estado do Maranhão 
em 1661, onde permaneceu até sua morte em 1698, em Belém. Durante os trinta e sete anos de missão na região, transitou entre os vários aldeamentos existentes, sendo responsável pela fundação do aldeamento do Tapajós que deu origem à cidade de Santarém. Exerceu várias funções na Companhia de Jesus, chegando a ser superior da missão e reitor dos colégios de Santo Alexandre (Belém) e Nossa Senhora da Luz (São Luís).

A proposta de escrever uma crônica da missão dos padres jesuítas no Estado do Maranhão partiu do Padre Bento Oliveira, quando este era superior da missão. Coube, contudo, à Bettendorff a tarefa de escrevê-la por ser, segundo ele, o missionário mais antigo com mais informações para relatar (BETTENDORFF, 1990).

A cópia manuscrita da crônica se encontra no setor de obras raras da biblioteca da Universidade de São Paulo (Coleção Yan Almeida Prado). A primeira publicação foi realizada em 1910 na Revista do Instituto Histórico Geográfico Brasileiro e, em 1990, a Secult/PA a reimprimiu (ARENZ, 2010). Esta versão contém seiscentas e noventa e sete páginas e está dividida em dez livros sem um rigor cronológico, pois o autor retoma, em vários momentos, acontecimentos de épocas anteriores. O Quadro 1 a seguir resume os temas abordados em cada um desses livros:

Quadro 1 - Descrição da crônica de Bettendorff, 1990.

\begin{tabular}{|c|l|l|}
\hline LIVRO & \multicolumn{1}{|c|}{ TÍTULO } & \multicolumn{1}{c|}{ ASSUNTO } \\
\hline 1 & $\begin{array}{l}\text { Da origem do nome, } \\
\text { descobrimento do Estado e } \\
\text { capitania do Maranhão }\end{array}$ & $\begin{array}{l}\text { Descrição e história do Estado do Maranhão em } \\
\text { que detalha as capitanias e missões existentes. }\end{array}$ \\
\hline 2 & $\begin{array}{l}\text { Do que obraram os Padres } \\
\text { missionários em tempo do } \\
\text { governo do primeiro } \\
\text { governador do Estado, e do } \\
\text { segundo em que fez a viagem } \\
\text { para Quito, e do terceiro, em } \\
\text { que os holandeses tomaram o } \\
\text { Maranhão. }\end{array}$ & $\begin{array}{l}\text { O autor faz uma descrição minuciosa da } \\
\text { expedição patrocinada pelo rei Felipe II que } \\
\text { intentava abrir caminhos mais rápidos até a } \\
\text { colônia espanhola no Peru. Relata o levante } \\
\text { popular que expulsou os holandeses do } \\
\text { Maranhão e ressalta o papel de Antonio Vieira } \\
\text { como responsável pela efetivação da missão no } \\
\text { Estado, em 1653, ao conquistar o governo } \\
\text { temporal dos indígenas garantindo o seu } \\
\text { aldeamento, condição decisiva para a catequese. }\end{array}$ \\
\hline
\end{tabular}




\begin{tabular}{|c|c|c|}
\hline 3 & $\begin{array}{l}\text { Do que os padres obraram } \\
\text { desde o ano de } 1655 \text { até o ano } \\
\text { da sua primeira expulsão, em } \\
1661 .\end{array}$ & $\begin{array}{l}\text { Focaliza as ações de Antonio Vieira e suas } \\
\text { conquistas para o desenvolvimento da missão } \\
\text { como a escrita do regulamento dos aldeamentos } \\
\text { - A visita, bem como a luta contra a escravidão } \\
\text { indígena. Detalha a distribuição dos } \\
\text { missionários pelas missões no Estado, incluindo } \\
\text { sua própria chegada na missão em 1661, e sua } \\
\text { primeira experiência em terras amazônicas. } \\
\text { Para escrever esses relatos é provável que ele } \\
\text { tenha utilizado as cartas do próprio padre } \\
\text { Vieira. }\end{array}$ \\
\hline 4 & $\begin{array}{l}\text { Levantamento do povo do } \\
\text { Maranhão e Pará contra os } \\
\text { padres da Companhia de } \\
\text { Jesus, enquanto se institui a } \\
\text { missão do rio das Amazonas } \\
\text { com missionários e } \\
\text { residências em Tapajós. }\end{array}$ & $\begin{array}{l}\text { São detalhadas sua experiência quando do } \\
\text { primeiro levante contra os jesuítas em 1661, } \\
\text { momento em que estava na missão do Tapajós e } \\
\text { por isso acabou escapando da expulsão por ter } \\
\text { se escondido na mata. }\end{array}$ \\
\hline 5 & $\begin{array}{l}\text { Do que se obrou do ano de } \\
1667 \text { até o ano } 1684\end{array}$ & $\begin{array}{l}\text { Narra o desenvolvimento da missão destacando } \\
\text { a criação do bispado em } 1680 \text { e o comércio das } \\
\text { drogas do sertão - cravo, cacau e as salinas dos } \\
\text { padres. Ressalta a promulgação da lei que } \\
\text { proibia a escravização do índio em } 1680 \text { e os } \\
\text { distribuía entre colonos e padres. }\end{array}$ \\
\hline 6 & $\begin{array}{l}\text { Das cousas que sucederam a } \\
\text { missão em tempo do governo } \\
\text { do Padre Pero Luiz Gonsalvi, } \\
\text { Romano. }\end{array}$ & $\begin{array}{l}\text { Relata sua experiência como reitor do Colégio } \\
\text { Nossa Senhora da Luz em São Luís iniciado em } \\
1674 \text { e diversas situaçôes vividas entre os padres } \\
\text { da companhia e o governo do Estado do } \\
\text { Maranhão demonstrando a inter-relação entre o } \\
\text { governo temporal e o espiritual com o destaque } \\
\text { para a nomeação do primeiro bispo do Estado, } \\
\text { D. Gregório dos Anjos. }\end{array}$ \\
\hline 7 & $\begin{array}{l}\text { Do levantamento do povo do } \\
\text { Maranhão, expulsão e } \\
\text { restituição dos padres } \\
\text { missionários da Companhia } \\
\text { de Jesus. }\end{array}$ & $\begin{array}{l}\text { Trata da Revolta de Beckman em que a disputa } \\
\text { pela mão de obra do trabalho indígena ocasiona } \\
\text { nova expulsão dos jesuítas do Estado do } \\
\text { Maranhão em 1684. Bettendorff foi deportado } \\
\text { inicialmente para o Estado do Brasil, e eleito } \\
\text { representante da missão para tratar das } \\
\text { questões em torno do governo temporal dos } \\
\text { índios na corte em Lisboa de onde retornou em } \\
\text { 1687. Suas negociações favoreceram a } \\
\text { promulgação do Regimento das missões em } \\
1688 \text { que devolveu aos jesuítas os poderes legais } \\
\text { no manejo do nativo. }\end{array}$ \\
\hline 8 & $\begin{array}{l}\text { Põe-se a missão em estado } \\
\text { maior e sua última } \\
\text { consistência. }\end{array}$ & $\begin{array}{l}\text { Relata os detalhes da missão na retomada do } \\
\text { governo temporal e espiritual dos índios como o } \\
\text { zelo no cuidado com as igrejas e capelas. } \\
\text { Também aborda as vicissitudes enfrentadas } \\
\text { nesse período como uma epidemia de varíola } \\
\text { ocorrida em } 1695 \text { que vitimou a maioria das } \\
\text { pessoas do colégio do Maranhão, das aldeias e } \\
\text { engenhos dos inacianos. A epidemia iniciada em } \\
\text { São Luís se estendeu por várias vilas incluindo } \\
\text { algumas da capitania do Pará e cidade de Belém. }\end{array}$ \\
\hline
\end{tabular}




\begin{tabular}{|c|l|l|}
\hline 9 & $\begin{array}{l}\text { Relata-se a repartição das } \\
\text { missões que se fez, por ordem } \\
\text { de Sua Majestade entre os } \\
\text { missionários das religiões e o } \\
\text { que obrou superior novo, } \\
\text { Bento de Oliveira, em tempo } \\
\text { de seu governo. }\end{array}$ & $\begin{array}{l}\text { Trata do conflito quanto às áreas de atuação das } \\
\text { diversas ordens religiosas já estabelecidas na } \\
\text { Amazônia no final do século XVII ficando a } \\
\text { região do Cabo Norte (Macapá) a cargo dos } \\
\text { Capuchos da Piedade. }\end{array}$ \\
\hline 10 & $\begin{array}{l}\text { Trata-se das cousas da missão } \\
\text { acontecidas em tempo do } \\
\text { superiorado do Padre José } \\
\text { Ferreira. }\end{array}$ & $\begin{array}{l}\text { Narra os conflitos entre o governador do Estado } \\
\text { do Maranhão como o novo bispo no final do } \\
\text { século XVII, motivados pelas divergências sobre } \\
\text { a jurisdição sobre as relações civis dos } \\
\text { habitantes do Estado. A crônica se encerra sem } \\
\text { o desfecho final da contenda. }\end{array}$ \\
\hline
\end{tabular}

Fonte: Buecke (2019).

Também é importante mencionar o Tesouro descoberto no máximo Rio Amazonas (1758-1776) (2004), do jesuíta português João Daniel que, em 1741, embarcou em Lisboa em direção às missões do Grão Pará, onde esteve por 16 anos. Em 1757, foi desterrado para a Corte sendo preso e assim permanecendo até a sua morte em 1776. Durante os anos de prisão, escreveu sua monumental obra de quase 800 páginas, baseando-se em suas memórias do período em que viveu na Amazônia.

Sua obra é marcada pelos relatos detalhados da geografia e natureza amazônica. De acordo com Abbate, (2016, p. 30) "O Tesouro diferencia-se, ainda, dos demais escritos de religiosos, por ser um tratado, ou seja: conjunto de estudos e propostas para melhor desenvolver as potencialidades econômicas da Amazonia”. Dentre os temas encontrados no Tesouro, destacamos:

- Da caça no Rio Amazonas;

- Das plantas e ervas notáveis;

- Das tintas;

- Da farinha de pão da América;

- Dos engenhos de açúcar;

- Das missões;

- Da pesca no Amazonas; 
- Da navegação;

- Das especiarias e riquezas;

- Dos pajés e suas feitiçarias.

Todos esses temas possibilitam ao leitor a compreensão da vida cotidiana na Amazônia, atravessada por práticas de sociabilidades, trocas culturais, por onde perpassavam uma rede de saberes, configurando essas práticas como educativas.

Além das crônicas dos religiosos, outro tipo de fonte significativa para a pesquisa educacional no período colonial são as cartas jesuíticas. As missivas eram instrumentos para a manutenção e fortalecimento do vínculo entre os membros da Companhia de Jesus e tinham o papel de fazer circular toda e qualquer informação vinda das localidades em que estavam instalados. Por isso, trazem relatos pormenorizados da vida na Colônia e da atuação dos jesuítas que contribuem para a compreensão do cotidiano social, bem como das práticas educativas nele imbricadas (BUECKE, 2019).

Nesse sentido, as cartas do padre Antônio Vieira disponíveis na coleção Cartas organizadas pelo historiador João Lúcio de Azevedo e publicadas pela Editora Globo, em 2008, configuram-se como mais uma rica fonte que pode contribuir com a escrita da história da educação na Amazônia Colonial. A coleção é composta de 3 volumes, totalizando 729 epístolas. A primeira edição desta obra ocorreu entre 1925-1928 lançada pelo próprio João Lúcio de Azevedo (VIEIRA, 2008).

Antonio Vieira (1608-1697) destacou-se no século XVII como fluente orador e escritor. Seus sermões foram considerados impactantes e podem ser encontrados em diversas coletâneas, como na edição da Martin Claret, Sermões escolhidos (2011). Em 1652, ele deixou o Estado do Brasil a fim de reestruturar a missão jesuítica do Estado do Maranhão e Grão-Pará. Esteve na região amazônica até 1661, quando foi expulso pelos moradores devido ao seu posicionamento contrário à escravização dos indígenas pois, no seu entender, os 
índios deveriam ser livres para serem catequisados.

Enquanto esteve na Missão do Maranhão, Vieira manteve intensa comunicação com os reis de Portugal e o superior da missão, de modo que seus relatos trazem informações importantes para se compreender o cotidiano vivido naquele período. Além disso, “a fim de normatizar o cotidiano dos aldeamentos, o padre Vieira enumerou 50 itens a serem observados pelos religiosos na convivência com os indígenas, dentre os quais destacou a educação dos curumins" (BUECKE, 2019, p. 35).

Mesmo após deixar a região norte em 1661, a influência de Vieira permaneceu através desse regulamento que continuou sendo seguido pelos jesuítas durante todo o século XVII e meados do século XVIII. O texto, que ficou conhecido como A visita, foi publicado por Serafim Leite (1943) no III Tomo de sua obra.

Os dez volumes produzidos por Serafim Leite sobre a História da Companhia de Jesus no Brasil configuram-se como outra importante fonte para os estudiosos do período colonial. Leite (1943) dedicou dois volumes de sua compilação à ação dos inacianos no Estado do Maranhão e Grão-Pará, nos quais aborda o funcionamento dos colégios existentes na região, entre outros assuntos pertinentes ao processo educativo. Alguns "detalhes" trazidos pelo historiador são matéria de questionamento e aprofundamento para os pesquisadores educacionais. Ele conta, por exemplo, que embora a disciplina fosse exigida dos estudantes, havia momentos de festejos como a celebração do dia de Santo Ignacio de Loyola (31/o7), em que os alunos faziam "algazarras e danças pelas ruas do Pará e Maranhão utilizando máscaras” (LEITE, 1943, p. 266).

Esse episódio demonstra que os colégios eram, sobretudo, espaços de mediação cultural em que o esforço de representação das culturas envolvidas gerava momentos de tensão e de transformação (MONTERO, 2006). Por mais que os jesuítas intentassem ordenar o funcionamento da colônia aos moldes cristãos, os estudantes do colégio também impunham novas formas de relação. 
A obra de Serafim Leite (1943), embora quase centenária, permanece importante, também por ter sido lastreada em vasta pesquisa documental. O historiador buscou fontes em diversos arquivos do Brasil e de Lisboa, escrevendo um texto robusto e bem fundamentado. Dentre os documentos por ele utilizados, estão cartas produzidas por outros atores envolvidos no processo de colonização da Amazônia, dentre as quais se destacam as cartas régias e de outras autoridades. Esses documentos, atualmente, podem ser encontrados nos Arquivos Históricos Ultramarinos de Lisboa através do Projeto Resgate Barão do Rio Branco. ${ }^{1}$ Existem outras documentações, tais como registro de consultas aos governantes e seus pareceres sobre variados assuntos, que podem responder e/ou subsidiar diversas questões no âmbito educacional voltadas para espaços não institucionais. ${ }^{2}$

Com o exposto, é possível desmistificar a ideia de que não existem fontes disponíveis para subsidiar e/ou sustentar a pesquisa educacional no período colonial amazônico. Os documentos aqui apresentados podem ajudar a responder muitas questões ainda sem respostas sobre como ocorria a educação naquele período - quer seja a que ocorria em âmbito institucional ou nos processos de socialização cotidianos.

No levantamento de trabalhos existentes, percebemos a potência e as possibilidades no que tange à pesquisa no período colonial e, por isso, apresentamos algumas delas, almejando apontar rumos ou suscitar novas questões a respeito do que ainda pode e deve ser estudado sobre a educação

\footnotetext{
1 O Projeto Resgate de Documentação Histórica Barão do Rio Branco foi criado institucionalmente, em 1995, por meio de protocolo assinado entre as autoridades portuguesas e brasileiras no âmbito da Comissão Bilateral Luso-Brasileira de Salvaguarda e Divulgação do Patrimônio Documental (Coluso). Tem como objetivo principal disponibilizar documentos históricos relativos à História do Brasil existentes em arquivos de outros países, sobretudo Portugal e demais países europeus com os quais tivemos uma história colonial imbricada. Fonte: http://www.cmd.unb.br/resgate_index.php.

2 Os documentos referentes ao Estado do Maranhão e Grão-Pará podem ser acessados nos sites: http://resgate.bn.br/docreader/DocReader.aspx?bib=013_PA\&PagFis=1\&Pesq=http://resgat e.bn.br/docreader/DocReader.aspx?bib=009_MA. Os catálogos com a descrição dos documentos referentes estão disponíveis nos endereços: https://actd.iict.pt/eserv/actd:CUc013/CU-Para.pdf https://actd.iict.pt/eserv/actd:CUcoo9/CU-Maranhao.pdf.
} 
colonial amazônica.

\section{A PRODUÇÃO CIENTÍFICA SOBRE EDUCAÇÃO NA AMAZÔNIA COLONIAL}

A partir do levantamento realizado, selecionamos trabalhos que focalizam a educação na Amazônia Colonial nos seus mais variados aspectos. Discorremos sobre alguns deles no intuito de apresentá-los, ainda que de maneira geral, e vislumbrar possibilidades de pesquisa.

Inicialmente, expomos o artigo Quem doutrine e ensine os filhos daqueles moradores: a Companhia de Jesus, seus colégios e o ensino na Amazônia colonial (2011) de Rafael Chambouleyron, Karl Heinz Arenz e Raimundo Moreira das Neves. Estes autores têm se destacado no estudo da Amazônia Colonial, concentrando sua produção bibliográfica naquele período. Outros artigos escritos por eles acerca da educação na Amazônia Colonial são: Além das doutrinas e rotinas: índios e missionários nos aldeamentos jesuíticos da Amazônia portuguesa (ARENZ, 2014); Sem educação não há missão: a introdução da formação jesuítica no Maranhão e Grão-Pará (Século XVII) (ARENZ, 2016).

Vale ressaltar que esses pesquisadores desenvolvem suas pesquisas no Programa de Pós-Graduação em História na UFPA, evidenciando a lacuna desses trabalhos nos Programas de Pós-Graduação em Educação.

No artigo em questão, os autores enfocam o trabalho dos jesuítas enquanto ordem educadora, como se pode depreender do excerto abaixo:

O ensino jesuítico é conhecido desde o princípio da Ordem, quando, como define um biógrafo de Santo Inácio, a Companhia de Jesus, inicialmente missionária, pouco a pouco se transformou numa 'Ordem docente' (GARCÍA-VILLOSLADA, 1991, p. 833). Pouco depois de sua fundação, a Companhia de Jesus orientou seus objetivos não somente para a instrução de seus próprios membros, mas também dos jovens 
em geral. Desta maneira, como explica Josette La Roche, os jesuítas buscaram 'ensinar as letras e a virtude à juventude, com o objetivo de fazê-la um meio de promoção dos valores defendidos pela Companhia, em seu mundo' (LA ROCHE, 1996, p. 194). (CHAMBOULEYRON, ARENZ e ALVES NETO, 2011, p. 62).

Dentre a bibliografia utilizada por Chambouleyron, Arenz e Alves Neto (2011), cabe destacar a dissertação Educação na Amazônia Colonial: Contribuição à história da educação brasileira de Garcilenil do Lago Silva, realizada no Programa de Pós-Graduação em Educação na PUC-RJ, em 1976. É sem dúvida um trabalho pioneiro, publicado em 1985, cuja edição se encontra esgotada. A biblioteca do Instituto de Ciências da Educação (ICED)-UFPA conta com um exemplar do texto que foi utilizado nesta análise.

Silva (1976) considera que a educação na Amazônia Colonial pode ser dividia em três grandes períodos, baseadas em três importantes legislações (Quadro 2):

Quadro 2 - Períodos da educação na Amazônia Colonial.

\begin{tabular}{|c|c|c|}
\hline PERÍODO & LEGISLAÇÃO & DESCRIÇÃO \\
\hline 1616-1757 & $\begin{array}{c}\text { Regimento das missões: Decretado por } \\
\text { Pedro II, Rei de Portugal, em 21 de } \\
\text { dezembro de 1686, por meio de 24 } \\
\text { parágrafos, concedia o direito de tutela } \\
\text { dos nativos capturados aos missionários } \\
\text { portugueses. }\end{array}$ & $\begin{array}{c}\text { Nesse período a educação } \\
\text { estava ao encargo das } \\
\text { ordens religiosas }\end{array}$ \\
\hline $1757-1798$ & $\begin{array}{c}\text { Diretório dos índios: Elaborada em 1755, } \\
\text { e publicada em 1757, por D. José I, rei de } \\
\text { Portugal, através de seu ministro, o }\end{array}$ & $\begin{array}{c}\text { Período em que a } \\
\text { educação passa a ter um } \\
\text { caráter laico. }\end{array}$ \\
& $\begin{array}{c}\text { Marquês de Pombal, essa legislação } \\
\text { elevava os aldeamentos indígenas à } \\
\text { condição de vilas ou aldeias, }\end{array}$ & \\
& administradas por um diretor & Correspondente à \\
& Regimento provisional para os & primeira tentativa de \\
& professores de Filosofia, Retórica, \\
& Gramática, e de Primeiras Letras no \\
& Estado do Grão Pará, publicada em o3 de & sistematização do ensino \\
& setembro de 1799. & na região. \\
\hline
\end{tabular}

Fonte: elaborado pelas autoras. 
Ao utilizar as legislações como marcos para entender a educação ocorrida no período colonial amazônico, a autora aponta para as possibilidades de estudos a partir das normas vigentes. Nesse sentido, cabe destacar a pesquisa de Damasceno (2012) que teve por objetivo desvelar a gênese da educação estatal na América Portuguesa baseando-se na lei que instituiu o Diretório dos Índios. Na tese, publicada em livro sob o título: Espadas, terços e letras: origens da Educação Estatal na América Portuguesa (2012), o autor esmiúça as tensões e batalhas presentes nesse processo inicial de formulação de um proposta de educação da Coroa, em contraste com a realidade vivida na colônia, configurando-se, portanto, como um estudo fundamental para a compreensão da história da educação na Amazônia Colonial.

Outros trabalhos que se sobressaíram nas buscas realizadas foram: Os jesuítas e o ensino na Amazônia Colonial (CHAMBOULEYRON, 2007); Educação dos índios na Amazônia do século XVII: uma opção laica (COELHO, 2008); As razões de Estado e seus fracassos no Período Colonial: memória da educação no Pará (RODRIGUES, 2011); Os índios e a educação no Mundo Colonial: fronteira oeste da América portuguesa (PESOVENTO, 2015).

Sob o ângulo da educação ocorrida fora dos moldes formais, destacamos o livro Beberagens indígenas e educação não escolar no Brasil Colonial, de Albuquerque (2012). Nele, a autora analisa o consumo de bebidas fermentadas embriagantes entre os índios da Amazônia, especialmente, os Tupinambás, considerados por cronistas e viajantes como amantes das beberagens. Para tanto, a autora recorre às crônicas de viajantes que passaram pelo Brasil no referido período e cartas de missionários validando tais documentos como fontes de pesquisa. Em sua análise, os relatos sobre as beberagens indicam que seu consumo era uma prática central na estruturação do cotidiano indígena, agindo ainda como instâncias de socialização. Fundamentada na história cultural, Albuquerque evidencia a dimensão educativa das beberagens uma vez que 
Atreladas a diversos e significativos momentos da vida cotidiana, no interior dessa prática um conjunto de saberes era posto em circulação, valores eram afirmados e a memória coletiva ativada, características essas que lhe confere um caráter eminentemente educativo (ALBUQUERQUE, 2012, p. 21).

Em vista disso, o livro é apontado pela prefaciadora, Thaís Fonseca, como "um estudo pioneiro no tratamento dado às questões da educação de natureza não escolar numa perspectiva histórica, ainda insatisfatoriamente explorada pela historiografia da educação brasileira” (ALBUQUERQUE, 2012, p. 17).

Na tese Colonização, catequese e educação no Grão-Pará de Anselmo Alencar Colares, defendida na Universidade Estadual de Campinas, em 2003, o autor apresenta um panorama geral da colonização brasileira e amazônica, enfatizando que, embora os interesses econômicos tenham sido os motivadores para tal empresa, "a religião naquele contexto, imbricada no poder do Estado, fazia com que as questões espirituais assumissem o mesmo grau de exigência que as necessidades práticas da vida” (COLARES, 2003, p. 102). Com isso, o trabalho de catequese e educação das ordens religiosas, particularmente, da Companhia de Jesus, tiveram papel fundamental na instrução dos habitantes da Amazônia no século XVII e XVIII.

Em 2016, foram defendidas duas dissertações cujos objetos de estudo concentram-se no período colonial amazônico, uma no Programa de PósGraduação em Educação da Universidade do Federal do Pará (UFPA) e outra no Programa de Pós-Graduação da Universidade do Estado do Pará (UEPA).

No trabalho intitulado Ação pedagógico-formativa da companhia de Jesus em Belém (1652-1759), Elizangela Costa focaliza, conforme indicado no título, a sistematização do trabalho jesuítico enquanto educadores em Belém. Para ela: 
Dentre as várias ordens religiosas que muito contribuíram para a colonizacão do Brasil, indubitavelmente, a Ordem dos Jesuítas foi a mais exitosa, pois possuía: muita disciplina, habilidades didáticas e, sobretudo, facilidade em aprender outros idiomas, fator ímpar para a aproximação e conquista dos silvícolas. Ademais, os inacianos possuíam apoio político (eles chegaram ao Brasil na caravela de Tomé de Souza, primeiro Governador Geral) e financeiro (por meio da redízima1) da Coroa portuguesa (COSTA, 2016, p. 18).

O segundo trabalho trata-se da dissertação $O$ que não mata, engorda: Cultura alimentar, mediadores culturais e educação na Amazônia Colonial de Francidio Monteiro Abbate, defendida no ano de 2016. A pesquisa analisa as trocas culturais envolvendo a questão alimentar entendidas como processos educativos. Ressalta que os hábitos alimentares na Amazônia no século XVIII demonstram a existência de trocas culturais entre brancos, negros e índios. Nesse processo, sobressai o papel da mulher índia como principal educadora e transmissora de conhecimentos acerca dos segredos da cozinha nativa. Era a cunhã quem repassava, primeiro à suas filhas e depois aos estrangeiros, os saberes necessários ao domínio da cozinha daquele período em que apenas conhecer a diferença entre o que era ou não comestível significava sobreviver ou morrer (BUECKE, 2019).

Para o autor, a relação alimentar estabelecida entre nativos e europeus demonstra, de um lado, a resistência dos silvícolas em abrir mão dos seus saberes, uma vez que as marcas da cozinha amazônica, do século XVIII, ainda estão presentes nos hábitos alimentares no norte do Brasil nos dias atuais. Por outro lado, revela a dependência dos adventícios em relação aos nativos já que não era possível manter aqui os mesmos hábitos alimentares que tinham em suas terras de origens em que as condições naturais da região e os costumes endêmicos produziam alimentos totalmente desconhecidos por eles.

Outro trabalho que merece relevo é a tese Luzes apagadas: a educação escolar indígena na Amazônia colonial de Jonas Cunha, defendida em 2018 na Universidade de São Paulo, São Paulo. A pesquisa de Cunha (2018) focaliza o papel das escolas de ler e escrever no século jesuíta (1616 a 1759), e das escolas 
régias no período pombalino, na civilização dos povos nativos na Amazônia. A seu ver, a cultura escolar trazida primeiro pelos religiosos e depois pelo pensamento ilustrado foi fundamental para a educação implementada na região. O autor ainda destaca que "a educação na Amazônia Colonial é um tema notoriamente despercebido pelos pesquisadores que investigam a história social e cultural da região" (CUNHA, 2018, p. 106).

A mais recente pesquisa situada no âmbito da Amazônia colonial encontrada foi a dissertação "Infância e práticas educativas na Amazônia Seiscentista”, de Jane Elisa Otomar Buecke, defendida em 2019 na UEPA. Ao perquirir crônicas e cartas de autores que descreveram, ainda que tacitamente, o cotidiano da Amazônia no século XVII, a autora considera a existência do sentimento de infância, notável pelos rituais de passagem que determinavam uma nova fase na vida tanto de meninos e meninas e pelas tarefas que lhes cabiam, as quais, mesmo como brincadeiras, apontavam para $o$ desenvolvimento do seu papel na tribo. Conforme Buecke (2019), as crianças aprendiam pela observação, repetição, imitação e silêncio, sendo importantes mediadoras culturais uma vez que os religiosos também aprendiam os saberes locais por meio delas dentre os quais a língua, a dança, a música, e os conhecimentos práticos se destacaram como principais.

Provavelmente, em função da maior oferta de fontes, os trabalhos ambientados na Amazônia Colonial incidem basicamente sobre a ação dos jesuítas. Sangenis e Maynka (2019) ressaltam a necessidade de por fim a essa supremacia, e apontam como alternativa os trabalhos da ordem Franciscana. Como principais argumentos, os autores destacam o longo período de atuação dos franciscanos no Brasil colonial - desde a chegada em 1500, até os dias atuais, e defendem que

os religiosos, indistintamente, por ordenação da Coroa, erigiam e administravam as aldeias de índios com o intuito de catequizar e civilizar os silvícolas. Frades e padres congregados pelos seus institutos construíam as suas escolas contíguas às igrejas. Nisso e em 
muitos outros encargos nada diferiam entre si. Todas as ordens contribuíram para construir a cultura brasileira e a mentalidade da sua população, a religiosidade popular, em regiões distintas e em períodos diferentes (SANGENIS; MAYNKA, 2009, p. 11).

Os autores sugerem fontes produzidas pelos franciscanos, ainda pouco investigadas, como os arquivos franciscanos de Recife e São Paulo nos quais é possível encontrar um vasto e variado acervo que merece a atenção dos pesquisadores do período colonial. Enfatizamos aqui as "iconografias (cerca de vinte mil imagens que abarcam paisagens regionais, monumentos, atividades religiosas e sociais, viagens, vida e costumes de povos indígenas das regiões Nordeste e Amazônica)" (SANGENIS; MAYNKA, 2019. p. 17). Ressaltamos o uso de imagens, como indícios que demandam maior atenção dos pesquisadores, pois

independentemente de sua qualidade estética, qualquer imagem pode servir como evidência histórica. Mapas, pratos decorados, ex-votos, manequins e os soldados de cerâmica enterrados nas tumbas dos primeiros imperadores chineses têm todos alguma coisa a dizer aos estudantes de história (BURKE, 2017, p. 28).

No sentido de ampliar as pesquisas sobre o período colonial para outras ordens, destacamos a tese de Maria Adelina Amorim, intitulada A missionação franciscana no estado do Grão-Pará e Maranhão: 1622-175o (2011). O segundo tomo da tese

é um elenco documental em que apresenta e transcreve cartas, decretos, consultas, relatórios, petições, certificados, processos judiciais, contratos, pareceres jurídicos e teológicos, inquirições, bem como bulas e breves papais, ofícios, cartas régias, memórias, termos, inventários de bens, registros de contabilidade, assentos de disputas entre os vários ramos da Ordem Franciscana, e com outras ordens e instituições públicas e privadas, assim como outros textos considerados importantes para o esclarecimento da problemática da missionação nos territórios do Maranhão e Grão-Pará durante os séculos XVII e XVIII, boa parte deles inédita" (SANGENIS; MAYNKA, 2019, p. 17). 
Além dos franciscanos e jesuítas, outras ordens tiveram papéis importantes na educação dos filhos dos colonos e dos índios que viveram na Amazônia colonial. Os mercedários focavam no ensino do latim e bons costumes aos filhos dos colonos e aceitavam os filhos da terra como noviços. Os carmelitas, por sua vez, mantiveram estabelecimentos de ensino em que preparavam centenas de nativos, com os quais organizavam orquestras (REIS, 1993). Nesse sentido, o papel exercido pelas diferentes ordens religiosas na educação amazônica configura-se como campo fértil de pesquisas a ser melhor delineado, demandando, por conseguinte, é um importante desafio aos estudiosos da história da educação.

\section{CONCLUSÃO}

A descrição de algumas fontes e de produções intelectuais voltadas para a educação na Amazônia colonial evidenciou que o foco do olhar tem sido a ação dos jesuítas como principais educadores na região, durante os séculos XVII e XVIII.

Nesse sentido, o estudo das ações educativas promovidas pelas diversas ordens religiosas que estiveram na região, a exemplo da congregação dos franciscanos, mercedários, carmelitas entre outros, constitui uma lacuna a ser superada pelas pesquisas histórico-educacionais.

Noutra direção, constatamos que, a despeito da existência de estudos históricos voltados para a análise de processos educativos ocorridos no cotidiano social, estes são ainda limitados, em face à educação escolarizada, ensejando aos historiadores da educação o desafio de ampliar a noção de educação de modo a incluir as diversas formas pelas quais as pessoas se socializavam no passado.

Uma possibilidade de compreender tanto a educação formal levada a efeito pelas diversas ordens religiosas, quanto os processos educativos 
vivenciados no cotidiano social da Amazônia colonial encontram-se nas Cartas, Crônicas e Relatos de Viagens, conforme procuramos evidenciar.

Essas fontes, embora publicadas e de fácil acesso, ainda são pouco utilizadas na seara da história da educação, corroborando a afirmação de Bittar e Ferreira (2010) de que pouco ainda se conhece sobre o passado colonial brasileiro.

Assim, esperamos que este artigo seja um estímulo a mais tanto no que concerne ao manuseio desses documentos, quanto à imersão dos pesquisadores no universo das práticas educativas ambientadas na colônia, sejam elas escolares ou não.

\section{REFERÊNCIAS}

ABBATE, Francidio Monteiro. O que não mata, engorda: cultura alimentar, mediadores culturais e educação na Amazônia Colonial. 2016. 132 f. Dissertação (Mestrado em Educação) - Centro de Ciências Sociais e Educação, Universidade do Estado do Pará, Belém, 2016. Disponível em: http://ccse.uepa.br/ppged/wpcontent/uploads/dissertacoes/10/dissertacao_francidio_monteiro_abate.pdf. Acesso em: 15 set. 2017.

ABBEVILLE, Claude. História da missão dos padres capuchinhos na ilha do Maranhão e suas circumvisinhaças. Maranhão: Typ. do Frias, 1874. Tradução de Cezar Augusto Marques. Disponível em: http://www2.senado.leg.br/bdsf/handle/id/221724. Acesso em: 14 nov. 2017.

\section{ALBUQUERQUE, Maria Betânia Barbosa. Beberagens indígenas e educação não escola no Brasil colonial. Belém: FCPTN, 2012.}

ARENZ, Karl Heinz. Do Alzette ao Amazonas: Vida e obra do padre João Felipe Bettendorff (1698). Revista de Estudos Amazônicos, Belém, v. 5, n. 1, p. 2578, 2010. Disponível em: http://etnolinguistica.wdfiles.com/local-files/artigo:arenz-2010/arenz_2010_bettendorff.pdf. Acesso em: 01 nov. 2016.

ARENZ, Karl Heinz. Além das doutrinas e rotinas: índios e missionários nos aldeamentos jesuíticos da Amazônia portuguesa (séculos XVII e XVIII). História e Cultura, Franca, SP, v. 3, n. 2, p. 63-88, jul./dez. 2014. Disponível 
em: https://ojs.franca.unesp.br/index.php/historiaecultura/article/view/996. Acesso em: 24 jul. 2017.

ARENZ, Karl Heinz. "Sem educação não há missão”: a introdução da formação jesuítica no Maranhão e Grão-Pará (Século XVII). Outros Tempos Pesquisa em Foco - História, [s.l.], v. 13, n. 21, p. 1-20, 30 jun. 2016. Universidade Estadual do Maranhão. http://dx.doi.org/10.18817/ot.v13i21.511. Disponível em:

http://www.outrostempos.uema.br/OJS/index.php/outros_tempos_uema/arti cle/view/511. Acesso em: 27 set. 2017.

ARQUIVO HISTÓRICO ULTRAMARINO DE LISBOA. Catálogo de documentos manuscritos avulsos referentes à capitania do Pará. Lisboa: AHU. Disponível em: https://actd.iict.pt/eserv/actd:CUco13/CUPara.pdf. Acesso em: 13 mai. 2019.

\section{ARQUIVO HISTÓRICO ULTRAMARINO DE LISBOA. Catálogo de} documentos manuscritos avulsos referentes à capitania do Maranhão. Lisboa: AHU. Disponível em:

https://actd.iict.pt/eserv/actd:CUcoo9/CU-Maranhao.pdf. Acesso em: 13 mai. 2019.

BETTENDORFF, João Felipe. Crônica da missão dos padres da Companhia de Jesus no Estado do Maranhão. 2. ed. Belém: Fundação Cultural Tancredo Neves; Secretaria de Estado da Cultura, 1990.

BITTAR, Marisa; FERREIRA JR., Amarílio. O estado da arte em história da educação colonial. Navegando pela história da educação brasileira, v. 1, p. 01-23, 2010.

BUECKE, Jane Elisa Otomar. Infância e práticas educativas na Amazônia Seiscentista. 2019. 121 f. Dissertação (Mestrado em Educação) Centro de Ciências Sociais e Educação, Universidade do Estado do Pará, Belém, 2019.

BURKE, Peter.Testemunha ocular: o uso de imagens como evidência histórica. Tradução de Vera Xavier dos Santos. São Paulo: Unesp, 2017. 153 p.

CHAMBOULEYRON, Rafael. Os jesuítas e o ensino na Amazônia colonial. Em Aberto, Brasília, v. 21, n. 78, p. 77-91, dez. 2007. Disponível em: http://rbep.inep.gov.br/index.php/emaberto/article/view/2210/2179. Acesso em: 28 nov. 2017.

CHAMBOULEYRON, Rafael; ARENZ, Karl Heinz; NEVES NETO, Raimundo 
Moreira das. "Quem doutrine e ensine os filhos daqueles moradores": a Companhia de Jesus, seus colégios e o ensino na Amazônia colonial. Revista HISTEDBR On-line, Campinas, v. 11, n. 43, p. 61-82, out. 2011. Disponível em: http://ojs.fe.unicamp.br/ged/histedbr/article/view/3165/2830. Acesso em: 21 dez. 2015.

COELHO, Mauro Cezar. Educação dos índios na Amazônia do século XVII: uma opção laica. Revista Brasileira de História da Educação, Maringá, v. 8, n. 3, p. 95-118, set./dez. 2008. Disponível em: http://www.rbhe.sbhe.org.br/index.php/rbhe/article/view/91/99. Acesso em: 28 nov. 2017.

COLARES, Anselmo. Colonização, catequese e educação no Grão-Pará. 2003. Tese (Doutorado em Educação) - Faculdade de Educação, Universidade Estadual de Campinas, SP, 2003.

COSTA, Elisangela Silva da. A ação pedagógico-formativa da Companhia de Jesus na cidade de Belém do Grão-Pará (1652-1759). 2016. 146 f. Dissertação (Mestrado) - Curso de Educação, Universidade Federal do Pará, Belém, 2016. Disponível em:

http://www.ppged.com.br/arquivos/File/DisElisangelaCostaPPGED2016.pdf. Acesso em: 28 mar. 2017.

CUNHA, Jonas Araújo da. Luzes apagadas: a educação escolar indígena na Amazônia Colonial. 2018. 210 f. Tese (Doutorado em Educação) - Faculdade de Educação, Universidade de São Paulo, São Paulo, 2018. Disponível em:

http://www.teses.usp.br/teses/disponiveis/48/48134/tde-14122018093140/en.php. Acesso em: o8 ago. 2019.

DAMASCENO, Alberto. Espadas, terços e letras: origens da educação estatal na América Portuguesa. Belém: Editora Açaí, 2012.

DANIEL, João. Tesouro descoberto no máximo rio Amazonas, v. 1 - 2. Rio de Janeiro: Contraponto, 2004.

ÉVREUX, Yves. Continuação da história das coisas mais memoráveis acontecidas no Maranhão nos anos de 1613 e 1614. Brasília: Senado Federal, 2007.

FERREIRA, Norma Sandra de Almeida. As pesquisas denominadas "Estado da Arte". Educação \& Sociedade [online.], v. 23, n. 79, p. 257-272, ago. 2002. Disponível em: http://www.scielo.br/pdf/es/v23n79/10857.pdf. Acesso em: 29 maio 2018. 
FIGUEIRA, Luís. Arte da língua brasílica. Lisboa: Oficina de Manoel da Silva, 1621.

FIGUEIRA, Pe. Luís. A Relação do Maranhão, 1608, pelo jesuíta Padre Luiz Figueira enviada a Cláudio Aquaviva. Revista do Instituto do Ceará. 1887, Tomo I, p. 97-138. Disponível em:

https://www.institutodoceara.org.br/revista/Rev-

apresentacao/RevPorAno/1903/1903-RelacaodoMaranhao1608.pdf. Acesso em: 13 nov. 2019.

FONSECA, Thais Nívia de Lima e. Letras, ofícios e bons costumes: civilidade, ordem e sociabilidade na América Portuguesa. Belo Horizonte: Autêntica, 2009.

JABOATÃO, Frei Antonio de Santa Maria. Novo orbe seráfico brasílico. Rio de Janeiro: Typ. Brasiliense de Maximiniano Gomes Ribeiro, 1858. 2 v.

Disponível em: http://www2.senado.leg.br/bdsf/handle/id/182923. Acesso em: 12 nov. 2019.

LEITE, Serafim. História da Companhia de Jesus no Brasil. Tomos III IV. Rio de Janeiro: Instituto Nacional do Livro, 1943.

LINS, Eugenio de Ávila. Novo orbe seráfico brasílico: o legado do Frei Jaboatam para a História da Arte Luso-brasileira. In: FERREIRA-ALVES, Natalia

Marinho. Os franciscanos no mundo português iii: o legado franciscano. Porto: Cepese, 2013. p. 355-373. Disponível em:

https://www.cepese.pt/portal/pt/publicacoes/obras/os-franciscanos-nomundo-portugues-iii-o-legado-franciscano/201cnovo-orbe-serafico-

basilico201d-o-legado-de-frei-jaboatao-para-a-historia-da-arte-luso-brasileirados-seculos-xvi-e-xvii>. Acesso em: 13 nov. 2019.

LISBOA, Frei Cristóvão de. História dos animais e árvores do Maranhão. Lisboa: Arquivo Histórico Ultramarino/Centro de Estudos Históricos Ultramarinos, 1967.

MONTERO, Paula. Deus na aldeia: missionários, índios e mediação cultural. São Paulo: Globo, 2006.

PESOVENTO, Adriane. Os índios e a educação no mundo colonial: fronteira oeste da América portuguesa. Revista Eletrônica de Educação, São Carlos, v. 9, n. 1, p. 9-26, 2015. Quadrimestral. Disponível em:

http://www.reveduc.ufscar.br/index.php/reveduc/article/view/1177. Acesso em: 28 nov. 2017. 
REIS, Arthur Cezar Ferreira. A política de Portugal no Valle Amazônico. Belém: Secult, 1993.

RODRIGUES, Denise Simões. As razões de Estado e seus fracassos no Período Colonial: memória da educação no Pará. Cocar, Belém, v. 10, n. 5, p.83-93, jul. 2011. Disponível em:

https://paginas.uepa.br/seer/index.php/cocar/article/viewFile/200/173. Acesso em: 28 nov. 2017.

SANGENIS, Luiz Fernando Conde \& MAINKA, Peter . Johann. (2019). Presença franciscana e supremacia jesuítica no campo da história e da história da educação na época colonial - um diagnóstico na pesquisa historiográfica a partir da análise dos CBHE da SBHE. Revista Brasileira de História da Educação,19. DOI: http://dx.doi.org/10.4025/rbhe.v19.2019.eo61

SEVERO, José Leonardo Rolim de Lima. Perspectivas curriculares sobre a formação do pedagogo para a educação não escolar. Educ. rev., Belo Horizonte, v. 34, e176656, 2018 . Disponível em:

http://www.scielo.br/scielo.php?script=sci_arttext\&pid=So10246982018000100124\&lng=pt\&nrm=iso. Acesso em: 15 nov. 2019. Epubo5Mar-2018. http://dx.doi.org/10.1590/0102-4698176656.

SILVA, Francisco Carlos Carvalho da; CAVALCANTE, Geórgia Gardênia Brito. A relação do Maranhão: a fúria de contrastes entre jesuítas e nativos no Ceará do século XVII. In: ENCONTRO INTERNACIONAL HISTÓRIA, MEMÓRIA, ORALIDADE E CULTURAS, 2012, Fortaleza. Anais... . Fortaleza: UECE, 2012. p. 1-14. Disponível em:

http://www.uece.br/eventos/encontrointernacionalmahis/anais/trabalhos_co mpletos/52-939-03102012-215554.pdf. Acesso em: 15 nov. 2012.

SILVA, Garcilenil do Lago. Educação na Amazônia Colonial: contribuição à história da educação brasileira. 1976. 1 v. Tese (Doutorado em Educação) Programa de Pós-Graduação em Educação, Pontifícia Universidade Católica, Rio de Janeiro, 1976.

SILVA, Nelly Monteiro Santos. A infância vivida em sobrados e mucambos: um olhar através de Gilberto Freire. In: CONGRESSO LUSO-BRASILEIRO DE HISTÓRIA DA EDUCAÇÃO, 6, 2006, Uberlândia. Anais... Uberlândia: Editora da UFU, 2006, p. 612-620.

SOUZA, Mariana Silveira Leornardo de. Espacializando a Historia do Brazil, de frei Vicente do Salvador. 2016, 130 f. Dissertação (Mestrado em História) - Instituto de Ciências Humanas, Universidade de Brasília, Brasília, 
2016. Disponível em:

https://repositorio.unb.br/bitstream/10482/24131/1/2016_MarianaSilveiraLe onardodeSouza.pdf. Acesso em: o9 de nov. 2019.

VIEIRA, Antônio. Cartas, v. 1, 2 e 3. Organização e notas, João Lúcio de Azevedo. São Paulo: Globo, 2008.

VIEIRA, Antônio. Sermões escolhidos. 4. ed. São Paulo: Martin Claret, 2011.

MARIA BETANIA BARBOSA ALBUQUERQUE é doutora em Educação: História, Política, Sociedade pela PUC/SP, com Pós-Doutoramento pelo CES-UC-Pt. Professora do Programa de Pós-Graduação em Educação da Universidade do Estado do Pará (UEPA), na Linha de Pesquisa: Saberes Culturais e Educação na Amazônia.

E-mail: mbetaniaalbuquerque@uol.com.br

(ib) http://orcid.org/0000-0002-9681-9293

JANE ELISA OTOMAR BUECKE é doutoranda em Educação no Programa de Pós-graduação da Universidade Federal do Pará com pesquisa concentrada em História da Educação na Amazônia Colonial. Mestra em Educação pelo no Programa de Pós-Graduação da Universidade do Estado do Pará (PPGED UEPA). Assessora Pedagógica da UEPA.

E-mail: janebuecke@yahoo.com.br

(i) http://orcid.org/0000-0001-5055-4210

Recebido em: 28 de agosto de 2019

Aprovado em: 20 de fevereiro de 2020

Revista História da Educação - RHE

Associação Sul-Rio-Grandense de Pesquisadores em História da Educação - Asphe

Artigo de acesso aberto distribuído nos termos de licença Creative Commons. 